\title{
O ensino dos jogos chineses: uma experiência nas aulas de educação física ${ }^{1}$
}

\author{
The teaching of chinese games: an experience in \\ physical education classes
}

\section{La ensenãnza de juegos chinos: una experiencia em clases de educación física}

\author{
iD Ho Shin Fú \\ Universidade de Pernambuco, Recife, Pernambuco, Brasil. \\ Email: hoshinfu19@gmail.com \\ iD (9) Pedro Henrique Bezerra da Silva \\ Universidade de Pernambuco, Recife, Pernambuco, Brasil. \\ Email: pedro.hbs01@gmail.com \\ iD Lívia Tenorio Brasileiro \\ Universidade de Pernambuco, Recife, Pernambuco, Brasil. \\ Email: livia.brasileiro@upe.br \\ iD Rodrigo Falcão Cabral de Oliveira \\ Universidade de Pernambuco, Recife, Pernambuco, Brasil. \\ Email: rodrigo.oliveira@upe.br \\ iD Marcelo Soares Tavares de Melo \\ Universidade de Pernambuco, Recife, Pernambuco, Brasil. \\ Email: mmelo19@hotmail.com
}

Resumo: Este estudo objetivou analisar as contribuições interculturais do ensino dos jogos chineses para a formação dos estudantes nas aulas de Educação Física. A pesquisa caracteriza-se como qualitativa do tipo participante, em que, para a coleta dos dados, foram utilizadas as filmagens e a observação-participante, e para a análise nos subsidiamos da

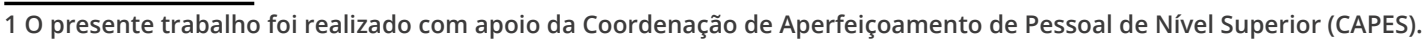


técnica de análise de conteúdo. Os dados obtidos indicaram que ensinar os jogos chineses nas aulas de Educação Física contribuiu significativamente para que os estudantes reconhecessem outra cultura e desenvolvessem competências através da sua prática. Assim, concluímos que a sua presença no ambiente escolar favorece a formação intercultural de um sujeito crítico e conhecedor de outros contextos que transcendem a sua própria realidade.

Palavras-Chave: Educação Física. Jogos Chineses. Prática Pedagógica.

Abstract: The study aimed to analyze the intercultural contributions of the teaching of Chinese games to the training of students in Physical Education classes. The research is characterized as qualitative of the participant type, where filming and participant observation were used for data collection, and for the analysis we subsidized the content analysis technique. The data obtained indicated that teaching Chinese games in Physical Education classes, significantly contributed for students to recognize another culture and develop skills through their practice. Thus, we conclude that their presence in the school environment favors the intercultural formation of a critical subject who knows other contexts that transcend their own reality.

Keywords: Physical Education. Chinese Games. Pedagogical Practice.

Resumen: El estudio tuvo como objetivo analizar las contribuciones interculturales de la enseñanza de juegos chinos a la formación de los estudiantes en las clases de Educación Física. La investigación se caracteriza por ser cualitativa del tipo participante, donde se utilizó el rodaje y la observación participante para la recolección de datos, y para el análisis subsidiamos la técnica de análisis de contenido. Los datos obtenidos indicaron que la enseñanza de juegos chinos en las clases de Educación Física, contribuyó significativamente a que los estudiantes reconocieran otra cultura y desarrollaran habilidades a través de su práctica. Así, concluimos que su presencia en el ámbito escolar favorece 
la formación intercultural de un sujeto crítico que conoce otros contextos que trascienden su propia realidad.

Palabras clave: Educación Física. Juegos chinos. Práctica pedagógica.

Submetido em: 28-05-2021

Aceito em: 07-07-2021 
O ensino dos jogos chineses: uma experiência nas aulas de educação física Ho Shin Fú • Pedro Henrique Bezerra da Silva • Lívia Tenorio Brasileiro • Rodrigo Falcão Cabral de Oliveira - Marcelo Soares Tavares de Melo

\section{Introdução}

Etimologicamente a palavra jogo deriva da palavra latina jocus, que significa graça ou escárnio, que, por sua vez, tem as suas origens enraizadas no latim clássico ludus, que significa divertimento ou recreação (HUIZINGA, 2000). Conforme o lexicógrafo Hoauiss (2001), a palavra jogo pode ser ainda utilizada para designar todas as atividades que possuem como natureza ou finalidade a recreação e o entretenimento.

Huizinga (2000, p. 33) interpreta o jogo como

uma atividade ou ocupação voluntária, exercida dentro de certos e determinados limites de tempo e espaço, seguindo regras livremente consentidas, mas absolutamente obrigatória.

Diante disso, destaca-se a ampla capacidade do jogo de envolver os seus praticantes devido aos sentimentos de tensão e alegria que são intrínsecos a sua prática e que propiciam uma fuga da vida cotidiana.

Ao longo da história o jogo tem se configurado como objeto de estudo de diversas áreas de conhecimento, dentre as quais podemos citar: a Filosofia, a Sociologia, a Psicologia, a Pedagogia e a própria Educação Física (CAILLOIS, 1990; KISHIMOTO, 1993; HUIZINGA, 2000; MELO, 2003; OLIVEIRA et al., 2016). No campo da Educação Física, mais especificamente, o jogo tem sido comumente abordado como conhecimento, conteúdo ou estratégia de ensino (MELO, 2003; OLIVEIRA et al., 2016).

Nesse contexto, o docente pode abordar o jogo como um fenômeno cultural arraigado de um caráter lúdico, visto que para Silva et al. (2012) é a partir da relação cultural que os sujeitos conseguem perceber o quanto o jogo é importante na esfera da vida. Assim, ressaltamos a importância do jogo ser ensinado de modo que os estudantes se apropriem das práticas corporais desenvolvi- 
O ensino dos jogos chineses: uma experiência nas aulas de educação física Ho Shin Fú • Pedro Henrique Bezerra da Silva • Lívia Tenorio Brasileiro • Rodrigo Falcão Cabral de Oliveira • Marcelo Soares Tavares de Melo

das historicamente pela humanidade, possibilitando a compreensão da própria cultura assim como das demais.

Para isso, é necessário termos o reconhecimento da existência dos diversos grupos sociais que formam a sociedade brasileira, uma vez que essa existência é decorrente de fatores que vão desde a colonização até os processos migratórios, aos quais o Brasil foi submetido durante o século XIX. Logo, salientamos que dentre os povos que se instalaram em terras brasileiras encontram-se os chineses e que, assim como tantos outros, também trouxeram a sua cultura milenar e a transmitiram através das gerações.

Miragaya $(2008$, p. 3) afirma que "o contato da China com outros povos, inclusive os ocidentais, a partir do século XIX fez com que características de outras nações fossem adicionadas à cultura chinesa",

como também o contrário, com a incorporação de alguns costumes e tradições chinesas pelos europeus, entre eles destacamse os seus jogos.

Dentre o acervo de jogos chineses, é notável a presença de uma grande variedade de práticas corporais que influenciaram na criação ou que possuem semelhanças com alguns jogos praticados no Ocidente, a exemplo: do Xianqi, considerado um dos precursores do Xadrez; do Mahjong, ancestral do Dominó; do Weiqi, predecessor das Damas e do Tsu-Chu, reconhecido como o embrião do futebol (KARMAN, 1978).

Para além desses, também é importante ressaltarmos a existência de outras práticas corporais que são consideradas como um misto de jogo e brincadeira, como é o caso do Tangram, do Diabolô e da Pipa (KARMAN, 1978). Sabendo ainda que todos esses jogos propiciam inúmeras contribuições aos praticantes nos mais variados aspectos.

Com base nisso, destacamos a importância de trabalhar esses jogos nas aulas de Educação Física a partir de um viés intercultural de ensino, que para Candau (2010, p. 338) 
O ensino dos jogos chineses: uma experiência nas aulas de educação física Ho Shin Fú • Pedro Henrique Bezerra da Silva • Lívia Tenorio Brasileiro • Rodrigo Falcão Cabral de Oliveira - Marcelo Soares Tavares de Melo

pretende ser uma proposta ética e política com o objetivo de construir sociedades democráticas que articulem a igualdade e o reconhecimento das diferentes culturas.

Assim, este estudo teve como objetivo analisar as contribuições interculturais do ensino dos jogos chineses para a formação dos estudantes nas aulas de Educação Física.

\section{Metodologia da pesquisa}

O presente trabalho trata-se de um recorte de uma pesquisa de mestrado intitulada "O Brasil e a China: aproximações entre os jogos nas aulas de Educação Física", e que pelo fato de envolver seres humanos, foi submetida ao Comitê de Ética e Pesquisa (CEP) com a aprovação outorgada no ano de 2019, tendo como número de Certificado de Apresentação para Apreciação Ética (CAAE) [19418619.7.0000.5192].

A pesquisa toma como embasamento a abordagem qualitativa, subsidiada pelo método da hermenêutica-dialética, e caracterizando-se como bibliográfica com inserção no campo através da pesquisa-participante,que, segundo Schimidt (2006), configura-se por pesquisador e pesquisados serem sujeitos e objeto do conhecimento e da natureza investigativa.

Em relação ao campo e aos sujeitos da pesquisa, informamos que esta envolveu toda uma unidade de ensino desenvolvida com 25 estudantes da turma do $6^{\circ}$ ano de uma escola da rede privada do município do Recife. A escolha pela escola ocorreu pelo fato do pesquisador também ser docente da instituição investigada e trabalhar o conteúdo dos jogos chineses durante as aulas de Educação Física. Enquanto que a opção pela turma do $6^{\circ}$ ano levou em consideração o maior tempo pedagógico que esta possuía para a vivência do conteúdo jogo em decorrência do calendário escolar. 
O ensino dos jogos chineses: uma experiência nas aulas de educação física Ho Shin Fú • Pedro Henrique Bezerra da Silva • Lívia Tenorio Brasileiro • Rodrigo Falcão Cabral de Oliveira - Marcelo Soares Tavares de Melo

Sobre os procedimentos para a coleta dos dados, utilizamos as filmagens e a observação-participante. A respeito das filmagens, Pinheiro, Kakehashi e Angelo (2005, p. 718) realçam a importância do seu uso "para o estudo de ações humanas complexas e difíceis de serem integralmente captadas e descritas por um único observador".

Em virtude disso, anunciamos que as filmagens foram utilizadas na intenção de captar momentos como o diálogo professor-estudante e estudante-estudante, a participação dos estudantes durante as atividades, as reações e expressões dos mesmos, como também a materialização do planejamento feito pelo professor.

Em relação à técnica da observação-participante, compreendemos que esta

permite que o observador chegue mais perto da vida dos sujeitos, um importante alvo nas abordagens qualitativas, na medida em que o observador acompanha in loco as experiências diárias dos sujeitos (LUDKE; ANDRÉ, 1986, p. 86).

Dessa maneira, a observação-participante nos possibilitou identificar aspectos como: a coerência das aulas com o planejamento; os conteúdos trabalhados nas aulas; os recursos e espaços utilizados; a interação dos estudantes entre eles e o professor; a avaliação das aulas e as contribuições e dificuldades encontradas no trato com o conteúdo.

Para a análise dos dados obtidos, nos subsidiamos da técnica de análise de conteúdo do tipo categorial por temática proposta por Bardin (2011), que se baseia "num recurso técnico para análise de dados provenientes de mensagens escritas ou transcritas" (SOUZA JUNIOR; MELO; SANTIAGO, 2010, p. 34). Assim, ressaltamos que as mensagens encontradas foram organizadas sob o formato de categorias e unidades para a criação de blocos temáticos que, por sua vez, foram identificadas a partir de palavras-chave. 
O ensino dos jogos chineses: uma experiência nas aulas de educação física Ho Shin Fú • Pedro Henrique Bezerra da Silva • Lívia Tenorio Brasileiro • Rodrigo Falcão Cabral de Oliveira - Marcelo Soares Tavares de Melo

Durante as análises dos dados, identificamos a categoria empírica Jogo e a partir dela encontramos as seguintes unidades de contexto e registro:

Quadro 1 - Categoria empírica e unidades de contexto e registro

\begin{tabular}{|c|c|}
\hline \multicolumn{2}{|c|}{ Categoria Empírica: Jogo } \\
\hline Unidades de Contexto & Unidade de Registro \\
\hline \multirow{4}{*}{ Jogos Chineses } & Divertido \\
\cline { 2 - 2 } & Regras \\
\cline { 2 - 2 } & Complexo \\
\cline { 2 - 2 } & Competição \\
\hline Jogos Brasileiros & Aproximações \\
\cline { 2 - 2 } & Fonte: Dados da pesquisa.
\end{tabular}

\section{Resultados e discussões}

Destacamos que as unidades de contexto e registro foram sendo explicitadas a partir do ensino dos jogos chineses nas aulas de Educação Física, sendo as mesmas apresentadas, neste estudo, articuladas as falas do professor e dos estudantes, auxiliando na identificação das contribuições teórico-metodológicas desses jogos.

A unidade de ensino foi planejada e estruturada no intuito de atender a proposta de ensino dos jogos chineses, conforme o quadro 2.

\section{Quadro 2 - Conteúdo programático}

\begin{tabular}{|l|c|l|}
\hline \multicolumn{2}{|c|}{ CRONOGRAMA } \\
\hline \multirow{4}{*}{ OUTUBRo } & $11 / 10$ & Leitura do texto didático. \\
\cline { 2 - 3 } & $18 / 10$ & Seminário: Jogos Chineses. \\
\cline { 2 - 3 } & $25 / 10$ & Construção dos tabuleiros e peças. \\
\hline \multirow{4}{*}{ NOVEMBRo } & $01 / 11$ & Vivência dos jogos construídos em sala. \\
\cline { 2 - 3 } & $08 / 11$ & História; Regras e Jogo: Jiànzi. \\
\cline { 2 - 3 } & $22 / 11$ & História; Regras e Jogo: Tsu - Chu/Futebol Chinês. \\
\hline
\end{tabular}


O ensino dos jogos chineses: uma experiência nas aulas de educação física Ho Shin Fú • Pedro Henrique Bezerra da Silva • Lívia Tenorio Brasileiro • Rodrigo Falcão Cabral de Oliveira - Marcelo Soares Tavares de Melo

Inicialmente, os estudantes foram subsidiados por um texto didático que abordava o conhecimento dos jogos chineses, visto que o uso desse recurso nas aulas de Educação Física contribui para armazenar e ampliar informações, esclarecer determinado assunto, ser uma fonte de consulta, facilitar a aprendizagem, promover o estudo independente, auxiliar na revisão de conteúdos, entre outros (SOUZA JUNIOR et al., 2015).

A leitura permitiu que os estudantes resgatassem em sua memória uma cultura lúdica anteriormente vivenciada, ao reconhecerem que alguns dos jogos descritos no texto já haviam sido praticados por eles em algum momento das suas vidas. Assim, para a surpresa do coletivo, os jogos chineses estavam inerentes em seu cotidiano mais do que imaginavam.

Além disso, a atividade também favoreceu o desenvolvimento da pesquisa escolar, uma vez que é incumbência do docente "incentivar o processo de investigação, contribuindo para um ensino de qualidade, em busca da crítica, da alegria e da transformação" (MELO, 2003, p. 59). Desse modo, ao buscar novas informações o estudante amplia o seu horizonte de conhecimentos e realiza um confronto com o que era aprendido anteriormente.

Após a leitura, os estudantes foram incentivados a escolherem um dos jogos chineses presentes no texto para serem apresentados sob o formato de um seminário, que entendemos como:

Uma forma de organização, com a intenção de confrontar o conhecimento, mediante análise dos objetivos propostos e síntese que visa a uma concretização dos objetivos finais, diante da elevação da qualidade do conteúdo sistematizado (PERNAMBUCO, 2013, p. 33).

Diante disso, a turma se dividiu em quatro grupos que optaram pela apresentação dos seguintes jogos: A) Tangram, B) Xianqi, C) Mahjong e D) Tsu-Chu. Com a apresentação dos seminários, os estudantes tomaram conhecimento da história, das regras e da forma de jogá-los, fato este que contribuiu significativamente para 
O ensino dos jogos chineses: uma experiência nas aulas de educação física Ho Shin Fú • Pedro Henrique Bezerra da Silva • Lívia Tenorio Brasileiro • Rodrigo Falcão Cabral de Oliveira - Marcelo Soares Tavares de Melo

as aulas posteriores. Ressalta-se que, durante as apresentações, os estudantes também destacaram a possibilidade de vivenciar os jogos chineses nas aulas de Educação Física.

Professor, eu acho que esses jogos poderiam ser trabalhados nas aulas de Educação Física, pois são parecidos com outros jogos que a gente já vivenciou, e os jogos chineses seriam mais alguns jogos que a gente poderia jogar nas aulas (ESTUDANTE A).

Eu também acho que sim professor, porque jogar esses jogos faz com que a gente conheça mais sobre outra cultura, sobre a história dela e sobre os próprios jogos (ESTUDANTE B).

Em prosseguimento, cada grupo ficou responsável por construir o seu próprio jogo durante a aula. Essa ação parte do entendimento de que o professor pode explorar durante as aulas a confecção

de materiais alternativos, porém não substitutivos aos equipamentos oficiais, explorando bastões, cordas, jornais, elásticos, sombrinhas, toalhas, lençóis, caixas, travesseiros, paredes, fitas, etc (BRASILEIRO; MARCASSA, 2008, p. 205).

Ao construírem os seus próprios jogos, os estudantes desenvolvem várias capacidades imprescindíveis para a sua formação, dentre as quais: o estímulo cognitivo, a destreza óculo-manual, a interação social, a capacidade de resolução de problemas, entre outros elementos que aliados ao momento lúdico despertam no sujeito a alegria e o prazer pela prática.

Em relação ao ato de jogar, percebemos que no decorrer do processo de construção, os estudantes adquiriram um maior conhecimento sobre os jogos e a sua prática, visto que ao se depararem com tabuleiros e peças que lhes eram até então desconhecidas, os mesmos foram provocados a buscarem um maior conhecimento sobre estas em outras fontes. 
O ensino dos jogos chineses: uma experiência nas aulas de educação física Ho Shin Fú • Pedro Henrique Bezerra da Silva • Lívia Tenorio Brasileiro • Rodrigo Falcão Cabral de Oliveira - Marcelo Soares Tavares de Melo

Nesse sentido, a turma vivenciou a prática dos jogos chineses utilizando os tabuleiros e as peças construídas anteriormente. Contudo, antes disso ocorreu o resgate da história e das regras de cada um dos jogos, haja vista que essa ação parte do princípio de que todo conhecimento deve ser espiralado, ou seja, durante o processo de ensino-aprendizagem tanto o professor quanto os estudantes devem estar num constante processo de idas e vindas aos conteúdos trabalhados em sala de aula (COLETIVO DE AUTORES, 2012).

Na sequência, os estudantes foram questionados sobre como poderiam classificar os jogos chineses. A partir disso, a turma atribuiu diferentes classificações ao jogo, como: esportivos, de tabuleiro, competitivos, populares, eletrônicos, de raciocínio e cooperativos. Com isso, o professou informou à turma que, dentre os vários tipos de jogos citados, os mesmos vivenciariam os jogos chineses tendo como referência a classificação proposta por Melo (2003), que os define como: esportivos, populares e de salão.

Nesse direcionamento, concordamos com o autor ao entendermos os jogos esportivos como aqueles que se aproximam do esporte institucionalizado, porém, com regras mais flexíveis. Por sua vez, os jogos populares caracterizam-se como aqueles que possuem um viés cultural e tendem a variar de região para região. Enquanto que os jogos de salão são aqueles que utilizam peças e tabuleiros pré-fabricados.

Em seguida, ficou definido com a turma um sistema de rodízio que propiciasse a prática dos três jogos para todos os participantes, sendo eles: o Tangram, o Xianqi e o Mahjong. O tempo estipulado para a duração de cada partida foi de cinco minutos. Ao final desse tempo todas as partidas deveriam ser encerradas e o rodízio realizado. Salientando que a definição do tempo teve como objetivo possibilitar que cada estudante jogasse pelo menos uma partida. Com essa definição todos da turma vivenciaram os jogos, apropriando-se desse conhecimento. 
O ensino dos jogos chineses: uma experiência nas aulas de educação física Ho Shin Fú • Pedro Henrique Bezerra da Silva • Lívia Tenorio Brasileiro • Rodrigo Falcão Cabral de Oliveira • Marcelo Soares Tavares de Melo

Destacamos que o rodízio apresentou-se como uma ótima estratégia metodológica, tendo em vista que conforme a atividade ia se desenvolvendo os grupos interagiam entre si, partilhando experiências e momentos como a própria disputa das partidas, a troca de informações e, sobretudo, a participação ativa na aula. Sobre a participação nas aulas, Melo (2003) realça que ela se configura como a base da relação pedagógica entre o docente e o discente no decorrer de todo o processo de ensino-aprendizagem.

Quando o estudante opta pela participação, ele percebe automaticamente que a sua ação é uma conquista e que contribuirá para o alcance de uma educação pautada pela alegria e pela transformação (MELO, 2003). Dessa forma, entendemos que a participação representa um ato político e, com isso, deve ser obtida mediante a luta dos professores e estudantes que anseiam por um ensino de qualidade.

Sobre as partidas, estas se mostraram momentos extremamente lúdicos pautados pelas disputas acirradas e leais do Xianqi e do Mahjong, e pela competição do Tangram em que os jogadores concorriam pela elaboração das figuras geométricas mais difíceis e inovadoras. Além disso, foi possível notarmos a presença de emoções como o prazer e a alegria tanto no semblante dos participantes como em suas falas.

Esse jogo é muito legal professor, a gente já tinha jogado na disciplina de Matemática, mas na aula de Educação Física o nosso olhar é diferente (ESTUDANTE A).

A gente deveria jogar mais jogos como esses nas aulas professor eles são muito divertidos (ESTUDANTE B).

Nesse instante surgiu a unidade de registro "divertido", visto que as falas dos estudantes enalteceram a diversão propiciada pela vivência de tais práticas. Diante disso, corroboramos com Santin (2001, p. 23) ao entender que o jogo "seria aquela dimensão vivenciada quando se pratica alguma atividade enquanto diversão". 
O ensino dos jogos chineses: uma experiência nas aulas de educação física Ho Shin Fú • Pedro Henrique Bezerra da Silva • Lívia Tenorio Brasileiro • Rodrigo Falcão Cabral de Oliveira - Marcelo Soares Tavares de Melo

Ademais, também entendemos que o princípio da diversão encontra-se atrelado a elementos como a participação e a interação com o outro, posto que esses aspectos ampliam as sensações de satisfação e alegria no praticante. Sobre esta última, Figueiredo (2017, p. 75) afirma que:

A escola tem condições de ter alegria, e, por isso, deve ter também como função proporcionar alegria aos estudantes ao longo do período de escolarização, além da preparação para o futuro. É somente a partir da alegria que os estudantes poderão ter a possibilidade de ignorar as distrações que os colocam para fora do contexto escolar.

Durante as análises, outra unidade de registro identificada foi "regras", que surgiu em razão das indagações feitas pelo professor sobre a implicação destas para a prática dos jogos chineses no decorrer da atividade.

O Xianqi é massa, ele é tipo o xadrez só que com outras regras (ESTUDANTE A).

Demorou pra entender algumas regras no começo, mas quando a gente começou a jogar, a gente foi entendendo melhor (ESTUDANTE B).

As regras configuram-se como um elemento essencialmente imbricado ao jogo, pois sem elas a prática dessas atividades torna-se impossível de acontecer. São as regras que definem o que é ou não permitido durante uma partida, podendo ampliar as ações do jogador como também criar algum impedimento (CAILLOIS, 1990; KISHIMOTO, 1993; HUIZINGA, 2000). Contudo, também é importante mencionar que: 
O ensino dos jogos chineses: uma experiência nas aulas de educação física Ho Shin Fú • Pedro Henrique Bezerra da Silva • Lívia Tenorio Brasileiro • Rodrigo Falcão Cabral de Oliveira - Marcelo Soares Tavares de Melo

Há jogos que não envolvem regras. Deste modo, não existem regras, pelo menos em termos fixos e rígidos, como brincar com as bonecas, os soldados, os caminhões [...] em geral, aos jogos que supõem uma livre improvisação e cujo principal atrativo advém do gozo de desempenharmos um papel, de nos comportarmos como se fossemos determinada pessoa ou determinada coisa (CAILLOIS, 1990, p. 28).

Além das regras, também evidenciamos a unidade de registro "complexo", graças aos relatos da turma sobre as dificuldades que foram encontradas ao jogarem os jogos chineses na aula. Com base nisso, outro fator que contribuiu para evidenciar essa unidade de registro foi a presença de elementos como raciocínio e estratégia em suas falas.

Eu achei que os jogos chineses são mais complexos do que os jogos praticados aqui no Brasil, eles necessitam de mais raciocínio e atenção dos jogadores (ESTUDANTE A).

A gente precisa ter muito raciocínio pra jogar esses jogos, principalmente, o Xianqi por causa das estratégias (ESTUDANTE B).

As constatações feitas pela turma encontram-se fundamentadas pelo fato de alguns jogos chineses apresentarem uma maior complexidade se comparados com outros jogos presentes no Brasil. Essa complexidade surge, muitas vezes, devido a fatores como o maior número de peças, o quantitativo superior de movimentações realizadas por elas, o objetivo do jogo, entre outros.

Contudo, essa mesma complexidade não pode ser interpretada como algo negativo, muito pelo contrário, as dificuldades que emergem mediante a prática desses jogos contribuem para que o sujeito descubra novas formas para resolução de problemas e desenvolva novas competências e habilidades. 
O ensino dos jogos chineses: uma experiência nas aulas de educação física

Ho Shin Fú • Pedro Henrique Bezerra da Silva • Lívia Tenorio Brasileiro • Rodrigo Falcão Cabral de Oliveira - Marcelo Soares Tavares de Melo

Posteriormente, os estudantes foram incentivados a relatarem sobre o que conheciam acerca do jogo Jiànzi. Nesse momento, eles mostraram desconhecimento, algo já esperado graças à nomenclatura e à própria popularidade do jogo. Em decorrência disso foi explicado um pouco da história dessa prática e a sua forma de jogar, assim como o objeto que serviria de base para toda a atividade, a peteca. Instantaneamente, os estudantes ficaram demasiadamente entusiasmados e, assim, o principal objetivo da aula foi anunciado. A turma vivenciaria o Jiànzi em seu modo formal e informal.

Nesse contexto, a atividade teve seu início com a proposição de que a turma fosse dividida em cinco times. Para cada time foi entregue uma peteca e, em seguida, as regras que regeriam toda a atividade foram delimitadas, sendo elas: os jogadores devem manter a peteca no ar sem deixá-la cair em nenhum momento; caso a peteca caia, o grupo automaticamente será o perdedor; para que a peteca se mantenha no ar os jogadores podem utilizar qualquer parte do seu corpo com exceção das mãos e dos braços.

Durante a atividade, os estudantes apresentaram uma dificuldade inicial para manter a peteca no ar. Logo, compreendemos que tal dificuldade denota a complexidade identificada nas aulas anteriores acerca dos jogos chineses, que contribuíram inclusive para o surgimento da unidade de registro "complexo". Porém, assim como nas práticas anteriores, as dificuldades que envolveram o Jiànzi foram solucionadas através das novas tentativas.

Em toda a disputa, os grupos se mostraram bastante animados para ganharem da equipe adversária, ao arriscarem um maior número de toques na peteca. Com o fim dessa atividade os estudantes já conseguiam dar até dez toques na peteca sem deixá-la cair ao chão. Na segunda atividade, os times foram mantidos e encorajados a jogarem o Jiànzi em seu modo formal. Para isso, a quadra foi dividida em dois segmentos no sentido horizontal utilizando uma corda amarrando-a nas traves presentes na quadra.

Em seguida, também foram delimitadas as seguintes regras: o objetivo do jogo é fazer a peteca transpor a linha e cair na quadra 
O ensino dos jogos chineses: uma experiência nas aulas de educação física Ho Shin Fú • Pedro Henrique Bezerra da Silva • Lívia Tenorio Brasileiro • Rodrigo Falcão Cabral de Oliveira - Marcelo Soares Tavares de Melo

adversária; os jogadores podem utilizar qualquer parte do corpo exceto as mãos e os braços para rebaterem a bola; as partidas acabam quando um time alcançar sete pontos.

Percebemos que a prática do Jiànzi se mostrou uma atividade bastante competitiva e dinâmica fazendo com que os participantes montassem estratégias e definissem alguns posicionamentos. Além de destacar os sentimentos de disputa e competitividade que, pautados pela noção de cooperação e honestidade, permearam toda a aula.

Após todos os grupos terem jogado entre si, a classe foi reunida para o momento final da aula, em que foi concedida, mais uma vez, a oportunidade de fala a fim de que pudessem relatar as suas experiências com o jogo e, mais precisamente, o que puderam compreender sobre que foi vivenciado na aula. Com essa abertura para a fala, conseguimos identificar outra importante unidade de registro, que foi "competição".

Esse jogo é muito legal, porque é algo novo e é sempre bom vivenciar atividades novas nas aulas, sem falar que ele também é um jogo competitivo (ESTUDANTE A).

Esse jogo é muito bom porque a gente pode competir com o colega pra ver quem consegue dar mais toques na peteca (ESTUDANTE B).

Em nossos estudos e observações, percebemos que o elemento da competição surge em momentos como a disputa, visto que conforme Caillois (1990) existe um conjunto de jogos que carregam a competição em sua gênese, caracterizando-se pela disputa em que as oportunidades são criadas artificialmente entre os jogadores com o objetivo de se confrontarem em condições de igualdade para que no fim haja um ganhador. 
O ensino dos jogos chineses: uma experiência nas aulas de educação física Ho Shin Fú • Pedro Henrique Bezerra da Silva • Lívia Tenorio Brasileiro • Rodrigo Falcão Cabral de Oliveira - Marcelo Soares Tavares de Melo

Trata-se sempre de uma rivalidade que se baseia numa única qualidade (rapidez, resistência, vigor, memória, habilidade, engenho, etc.), excedendo em limites definidos e sem nenhum auxiliar exterior, de tal forma que o vencedor apareça como sendo o melhor, numa determinada categoria de proezas (CAILLOIS, 1990, p. 34).

Nas observações também constatamos que trazer novas experiências para as aulas de Educação Física colabora para despertar a curiosidade dos estudantes sobre um conteúdo ou conhecimento. Assim, ao trazer um jogo como o Jiànzi para o cotidiano da turma, o docente estará instigando-os a expandirem o seu horizonte de conhecimentos, ao invés de relegá-los às práticas comuns ao seu dia a dia (CAILLOIS, 1990, HUIZINGA, 2000).

Destarte, nas aulas posteriores, os estudantes foram apresentados ao conteúdo do Tsu-Chu. Com isso, o coletivo foi questionado acerca do que conheciam sobre esse jogo, e durante esse processo o grupo que ficou responsável por apresentá-lo, sob o formato de um seminário na segunda aula da unidade, contribuiu de forma significativa para o diálogo, resgatando o contexto histórico e fazendo relação com o futebol moderno.

Nas nossas pesquisas, descobrimos que o futebol surgiu na Chi-
na e tinha o nome de Tsu-Chu, e naquela época a bola usada
para jogar era a cabeça dos inimigos conquistados. Para jogar
o Tsu-Chu é preciso ter mais de uma meta, e o número de joga-
dores também é maior, que são quatorze em cada time (ESTU-
DANTE A).

Dando continuidade à vivência, a aula foi dividida em dois momentos distintos. No primeiro, os estudantes foram instigados a jogarem o futebol em sua maneira mais conhecida, ou seja, na primeira parte da aula as atividades problematizadas estavam voltadas para o futebol moderno, esporte este que foi aperfeiçoa- 
O ensino dos jogos chineses: uma experiência nas aulas de educação física Ho Shin Fú • Pedro Henrique Bezerra da Silva • Lívia Tenorio Brasileiro • Rodrigo Falcão Cabral de Oliveira - Marcelo Soares Tavares de Melo

do na Inglaterra e tem suas regras estabelecidas pela Federação Internacional de Futebol Associado (FIFA).

Em relação às regras, estas foram modificadas com o objetivo de atender as demandas de um jogo formal, pois, apesar da atividade se desenvolver na quadra em vez de um campo, perspectivou-se respeitar as regras institucionalizadas do futebol, como exemplo: o jogador só poderia repor a bola pelas laterais da quadra utilizando obrigatoriamente as mãos.

Ao jogarem, os estudantes demonstraram uma grande afinidade com o jogo, muito disso em razão da grande massificação que o futebol possui no Brasil, chegando inclusive a ser considerado um esporte nacional. Em seguida, os estudantes foram apresentados ao Tsu-Chu ou futebol chinês, com isso também foi solicitado que os times se mantivessem, modificando apenas a ordem de quem jogaria primeiro.

Diferentemente do jogo anterior, que possuía apenas duas metas, nessa atividade foram definidas quatro metas a serem atingidas pelos participantes. Para aumentar o número de metas ocorreu a substituição das traves por cones, que, por sua vez, foram posicionados nas extremidades da quadra.

Ademais, informamos que o objetivo principal do jogo também foi modificado, passando a ser o seguinte: cada equipe poderá marcar o ponto em qualquer uma das duas metas adversárias, nesse sentido, será sagrada vencedora a equipe que realizar o maior número de pontos.

Em relação ao tempo ficou estipulado com o coletivo que cada partida teria a duração de cinco minutos. Ao término da aula, a turma foi reunida e os questionamos sobre as atividades em que foram iniciados.

Como vimos anteriormente, o futebol tem as suas origens na China com a prática do Tsu-Chu. Desta forma, o objetivo da aula foi apresentar para vocês esses dois jogos e as formas de jogá-los. Com isso, lhes pergunto sobre quais aproximações e di- 
O ensino dos jogos chineses: uma experiência nas aulas de educação física Ho Shin Fú • Pedro Henrique Bezerra da Silva • Lívia Tenorio Brasileiro • Rodrigo Falcão Cabral de Oliveira • Marcelo Soares Tavares de Melo

ferenças vocês puderam identificar acerca desses dois jogos? (PROFESSOR).

Imediatamente, a turma começou a citar várias opiniões, dentre as quais:

\begin{abstract}
Acho que em relação às aproximações entre os dois jogos a gente pode citar a bola que é a mesma, o uso dos pés para jogar e o número de jogadores. Já as diferenças, principal delas é o número de metas, pois no futebol tradicional são duas e no futebol chinês são quatro. Também tem a questão do goleiro que no futebol tradicional é obrigatório, mas no futebol chinês não (ESTUDANTE A).
\end{abstract}

A partir das falas do professor e dos estudantes, notamos a aparição das unidades de registro "aproximações" e "diferenças", sabendo que a proposta da experiência dos jogos chineses ao longo da unidade de ensino teve como objetivo instigar os estudantes a perceberem e refletirem sobre as aproximações e diferenças que essas práticas possuem com os jogos brasileiros. Sobre as aproximações e diferenças entre os jogos, notamos as seguintes percepções da turma sobre o conteúdo:

Professor, o Xianqi é um jogo muito parecido com o xadrez, pois a forma de jogar e o nome das peças são quase iguais. Porém, as peças se parecem mais com as damas (ESTUDANTE A).

O Tangram lembra um jogo de quebra-cabeça, já que a gente tem que encaixar as peças umas nas outras para formar uma imagem (ESTUDANTE B).

O futebol surgiu na China, e o Tsu-Chu foi o primeiro jogo que a gente pode considerar como sendo o futebol (ESTUDANTE C). 
O ensino dos jogos chineses: uma experiência nas aulas de educação física Ho Shin Fú • Pedro Henrique Bezerra da Silva • Lívia Tenorio Brasileiro • Rodrigo Falcão Cabral de Oliveira - Marcelo Soares Tavares de Melo

Nesse contexto, compreendemos que os jogos chineses, assim como os jogos presentes no Brasil, também passaram por um processo de evolução e mudança dos sentidos e significados ao longo tempo. Apesar dessas transformações históricas, é necessário reconhecermos a pertinência de resgatarmos essas práticas nas aulas de Educação Física, trazendo elementos de uma cultura tão rica como a chinesa.

Além disso, esse resgate apenas reforça o entendimento de que a escola caracteriza-se como um ambiente pautado pela interação entre as diversas culturas e, assim, possibilita que crianças e adolescentes interajam, trocando questionamentos, informações e conhecimentos (TRIANI; FONSECA; SBARAINI, 2015). No entanto, essa troca não deve acontecer de forma desatenta ou descompromissada, mas sim articulada com a orientação dos professores no intuito de alcançar uma educação intercultural.

Sobre a avaliação do conteúdo, informamos que esta aconteceu de forma interativa.Segundo Melo (2003, p. 60), esse tipo de avaliação

é necessária para a descoberta de novos conhecimentos inerentes a vida dos alunos, pois apresenta caminhos, mesmo com limitações, na busca de um novo ensino para as aulas de Educação Física.

Assim, os estudantes foram avaliados em todas as aulas acerca do que compreenderam em relação ao conteúdo dos jogos chineses, permeando desde a leitura do texto didático, perpassando as apresentações dos seminários, chegando à construção dos jogos e concluindo com as vivências deles.

\section{Considerações finais}

Diante disso, compreendemos que tratar de outras culturas a exemplo da chinesa, no ambiente escolar, não se configuraria 
O ensino dos jogos chineses: uma experiência nas aulas de educação física Ho Shin Fú • Pedro Henrique Bezerra da Silva • Lívia Tenorio Brasileiro • Rodrigo Falcão Cabral de Oliveira - Marcelo Soares Tavares de Melo

como algo impossível ou dispensável de realização, mas sim como algo que contribuiria imensamente para a formação de um sujeito crítico e conhecedor de outros contextos que transcendem a sua própria realidade.

Também evidenciamos diversas contribuições significativas para a formação dos estudantes, do ponto de vista cognitivo, motor ou cultural, que apenas reforçam a presença desses conteúdos nas aulas de Educação Física na intenção de ampliar o rol de práticas corporais existentes e, assim, qualificar o processo formativo dos sujeitos.

Por fim, a experiência com o conhecimento dos jogos chineses se mostrou exitosa, pois, ao conhecer e vivenciá-los nas aulas, o estudante amplifica o seu horizonte de conhecimento, não se limitando às atividades exclusivas da sua cultura, favorecendo assim o desenvolvimento de novas competências e habilidades, pois cada jogo carrega consigo uma complexidade operacional e um objetivo a ser alcançado.

\section{Referências}

BARDIN, Laurence. Análise de conteúdo. Lisboa: Edições 70, 2011.

BRASILEIRO, Lívia Tenorio; MARCASSA, Luciana Pedrosa. Linguagens do corpo: dimensões expressivas e possibilidades educativas da ginástica e dança. Pro-Posições, v. 19, n. 3, p. 195207, 2008.

CAILLOIS, Roger. Os Jogos e os Homens: a máscara e a vertigem. Lisboa: Cotovia. 1990.

CANDAU, Vera Maria. Educação intercultural na América Latina: concepções distintas e tensões atuais. Estudios pedagógicos, v. 36, n. 2, p. 333-342, 2010. 
O ensino dos jogos chineses: uma experiência nas aulas de educação física

Ho Shin Fú • Pedro Henrique Bezerra da Silva • Lívia Tenorio Brasileiro • Rodrigo Falcão Cabral de Oliveira • Marcelo Soares Tavares de Melo

COLETIVO DE AUTORES. Metodologia do ensino da Educação

Física. 2. ed. São Paulo: Cortez, 2012.

FIGUEIREDO, Marcela Natália de Lima. O Lúdico No Programa Segundo Tempo: uma análise da prática pedagógica dos professores de Educação Física da cidade do Recife. 2017. 187 f. Dissertação (Mestrado). Programa Associado de Pós-Graduação em Educação Física, Universidade de Pernambuco/ Universidade Federal da Paraíba. Recife. 2017.

FLEURI, Reinaldo Matias. Intercultura: estudos emergentes. ljuí: Unijuí, 2002.

HOUAISS, Antônio. Dicionário Houaiss da Língua Portuguesa. Rio de Janeiro: Objetiva, 2001.

HUIZINGA, Johan. Homo ludens: o jogo como elemento da cultura. 4. ed. São Paulo: Perspectiva, 2000.

KARMAN, Roger. Os Melhores Jogos do Mundo. São Paulo: Abril. 1978.

KISHIMOTO, Tizuko Morchida. Jogos Infantis: o jogo, a criança e a educação. 6. ed. Petrópolis: Vozes, 1993.

LUDKE, Menga; ANDRÉ, Marli. Pesquisa em educação: abordagens qualitativas. São Paulo: EPU. 1986.

MELO, Marcelo Soares Tavares. 0 ensino do jogo na escola: uma abordagem metodológica para a prática pedagógica dos professores de educação física. Recife: EDUPE, 2003.

MIRAGAYA, Ana. Jogos Olímpicos de Pequim: a cultura chinesa como base da renovação olímpica. Porto Alegre: Editora da UFRGS, 2008.

OLIVEIRA, Rodrigo Falcão Cabral et al. Analisando o Jogo a partir da Conceituação de Professores de Educação Física. Educação em Revista (UFMG), v.32, n.4, p. 323-343, out/dez, 2016.

PERNAMBUCO. Parâmetros para a Educação Básica do Estado de Pernambuco - Parâmetros Curriculares de Educação Física. Recife: UDIME, 2013. 
O ensino dos jogos chineses: uma experiência nas aulas de educação física Ho Shin Fú • Pedro Henrique Bezerra da Silva • Lívia Tenorio Brasileiro • Rodrigo Falcão Cabral de Oliveira • Marcelo Soares Tavares de Melo

PINHEIRO, Eliana Moreira; KAKEHASHI, Tereza Yoshiko; ANGELO, Margareth. O uso de filmagem em pesquisas qualitativas. Revista Latino-am de Enfermagem. v. 13, n. 5. p. 717-22, set./out. 2005. SANTIN, Silvino. Educação Física: da Opressão do Rendimento à Alegria do Lúdico. 3. ed. Porto Alegre: Edições EST/ESEF - UFRGS, 2001.

SCHMIDT, Maria Luisa Sandoval. Pesquisa participante: alteridade e comunidades interpretativas. Psicologia USP. v. 17, n. 2, p. 1141. out./nov. 2006.

SILVA, Glycia Melo de Oliveira et al. O jogo na escola: uma análise da intenção pedagógica de professores de Educação Física. Conexões: revista da Faculdade de Educação Física da UNICAMP. v. 10, n. 2, p. 145-164, mai./ago. 2012.

SOUZA JUNIOR, Marcílio Barbosa Mendonça; MELO, Marcelo Soares Tavares; SANTIAGO, Maria Eliete. A análise de conteúdo como forma de tratamento dos dados numa pesquisa qualitativa em Educação Física escolar. Movimento. Porto Alegre, v. 16, n. 3 , p. 31-49, jul./set. 2010.

SOUZA JUNIOR, Marcilio Barbosa et al. Educação Física e Livro Didático: entre o hiato e o despertar. Movimento (UFRGS. Impresso), v. 21, p. 479-493, 2015.

TRIANI, Andre Pereira; FONSECA, Ricardo Alves; SBARAINI, Fabiana Letícia. Educação Física Escolar, Interculturalidade e Saúde: uma articulação necessária. Ensino, Saúde e Ambiente. v. 8, n. 3, p. 1-14. nov./dez. 2015.

\section{Publisher}

Universidade Federal de Goiás. Faculdade de Educação Física e Dança. Publicação no Portal de Periódicos UFG. As ideias expressadas neste artigo são de responsabilidade de seus autores, não representando, necessariamente, a opinião dos editores ou da universidade. 